OPEN ACCESS

Edited by:

Fatemeh Karimi,

Quchan University of Advanced

Technology, Iran

Reviewed by:

Somaye Cheraghi,

Shahid Bahonar University of

Kerman, Iran

Vahid Arabali,

Islamic Azad University Sar

Branch, Iran

*Correspondence:

Feng Sun

sunfeng@wcsy-uni.cn

Specialty section:

This article was submitted to

Electrochemistry,

a section of the journal

Frontiers in Chemistry

Received: 18 April 2021

Accepted: 17 May 2021

Published: 31 May 2021

Citation:

Li C and Sun F (2021) GrapheneAssisted Sensor for Rapid Detection of

Antibiotic Resistance in

Escherichia coli.

Front. Chem. 9:696906.

doi: $10.3389 /$ fchem.2021.696906

\section{Graphene-Assisted Sensor for Rapid Detection of Antibiotic Resistance in Escherichia coli}

\author{
Chunlei $L^{1}{ }^{1}$ and Feng Sun ${ }^{2 *}$ \\ ${ }^{1}$ Department of Gastroenterology, Jiaozhou Central Hospital, Jiaozhou, China, ${ }^{2}$ Department of Colorectal and Anal Surgery, The \\ First Affiliated Hospital of Guangzhou University of Traditional Chinese Medicine, Guangzhou, China
}

In recent years, antibiotic-resistant bacteria caused by antibiotic abuse in the medical industry have become a new environmental pollutant that endangers public health. Therefore, it is necessary to establish a detection method for evaluating drug-resistant bacteria. In this work, we used Escherichia coli as a target model and proposed a method to evaluate its drug resistance for three antibiotics. Graphene dispersion was used to comix with $E$. coli cells for the purpose of increasing the current signal. This electrochemicalbased sensor allows the evaluation of the activity of $E$. coli on the electrode surface. When antibiotics were present, the electrocatalytic reduction signal was diminished because of the reduced activity of $E$. coli. Based on the difference in the electrochemical reduction signal, we can evaluate the antibiotic resistance of different $E$. coli strains.

\begin{abstract}
Keywords: electrochemical sensors, drug-resistant strains, activity determination, antibiotics, electrode modification, catalytic reduction current
\end{abstract}

\section{INTRODUCTION}

Antibiotics are secondary metabolites that can interfere with cell growth and development (Simioni et al., 2017; Wang M. et al., 2019). They are mainly of microbial origin. The biochemist Fleming first discovered penicillin in 1929. Penicillin played an important role in World War II and was very effective in controlling bacterial infections (Alsaiari et al., 2021). However, the harm of antibiotics to the human body should not be underestimated. For example, furacilin enters the human body through food and may cause cancer with long-term consumption (Hu et al., 2010). Similarly, the commonly used sulfonamide antibiotic sulfadimethoxine has tumorigenic effects (Zhuang et al,, 2019). According to the classification of chemical structure, antibiotics can be roughly divided into quinolone antibiotics, sulfonamide antibiotics, chloramphenicol antibiotics, aminoglycoside antibiotics, beta-lactam antibiotics and tetracycline antibiotics (Sharaha et al., 2017).

Large amounts of antibiotics are often used in the medical industry, and bacteria can develop resistance under the pressure of antibiotic selection. Antibiotic resistance genes (ARGs) are intrinsic to the development of drug resistance (Osman et al., 2021). Earlier studies have found that resistant bacteria are able to transfer the resistance genes they contain to other bacteria through animal excreta at the genetic level, eventually causing the large-scale presence of resistant bacteria (Hu et al., 2017).

Drug-resistant bacteria (ARB) are some bacteria that are originally sensitive and turn out to be resistant to drugs (Bengtson et al., 2017; Mulat et al., 2019). However, in low concentrations of antibiotics, some bacteria that were previously resistant tend to lose their resistance. This is because sensitive bacteria require fewer nutrients than resistant bacteria and have an advantage when competing with resistant bacteria, which inhibit the growth of resistant bacteria (Mishra et al., 2018; Sun et al., 2020). Therefore, reducing the abuse of antibiotics can reduce the risk of drug resistance. In 
general, long-term use of antibiotics tends to lead to the development of bacterial resistance (Gorlenko et al., 2020; Karimi-Maleh et al., 2020; Zhao et al., 2020). Bacterial resistance has become one of the top 10 global health threats, and its contamination is widespread and persistent. ARGs enter the human body through the food chain and cause an imbalance in the normal flora and increase the resistance of pathogenic and conditionally pathogenic bacteria in the body, posing a serious threat to the health of the body and disease control (Wang Y. et al., 2019; Karimi-Maleh et al., 2021a).

The traditional method for detection of bacterial resistance is the microbial inhibition method. Traditional microbial suppression methods are mostly based on bacterial isolation and culture methods, mainly for the detection of bacterial drug resistance phenotypes (Asghar et al., 2017; Zhou et al., 2017; Karimi-Maleh et al., 2021b, 2021c). The commonly used detection methods are mainly paper diffusion method and agar dilution method. The paper diffusion method is to apply a drugsensitive tablet to $\mathrm{M}-\mathrm{H}$ agar that has been inoculated with the bacteria to be tested, and then measure the inhibition circle after incubation. The size of the inhibition circle is closely related to the resistance of bacteria, and the strength of bacterial resistance to antibiotics is analyzed according to its size (Sedki et al., 2017). Polymerase chain reaction (PCR) is a molecular biology technique that allows rapid amplification of target genes. Compared with traditional microbial inhibition methods, this technique has the advantages of being less time-consuming and easier to perform, and it can also meet the requirements of simultaneous detection of large quantities of samples (Bagheri et al., 2019; Phung et al., 2020). However, the PCR technique also has some shortcomings, such as easy contamination. Even a very small amount of contamination can still cause false positives ( $\mathrm{Wu}$ et al., 2020; Zhang X. et al., 2020; Zhi-bin et al., 2021). Moreover, this technique is limited by the design of primers. Quantitative real-time fluorescent PCR (qPCR) is based on normal PCR, where a fluorescent dye or probe is added to the PCR reaction system to reflect the amount of PCR product in real time by changes in fluorescence signal. During the qPCR process, the entire process is monitored in real time, allowing the quantification of the amount of starting template (Waseem et al., 2019). The method is more specific, but expensive and not suitable for analysis of a large number of samples. Therefore, it is necessary to develop a rapid way to evaluate bacterial resistance.

In recent years, there have been recent advances in the electrochemical ultrasensitive detection of bacteria (Farooq et al., 2020; Fu et al., 2020; Khan et al., 2020; Zhang L. et al., 2020). The principle of electrochemical methods for detecting bacterial drug sensitivity is that bacterial respiration relies mainly on electron transfer in the respiratory chain, and the coincidental introduction of redox probes intervenes in the bacterial respiratory chain. The electrochemical changes generated by the respiratory chain activity can be detected rapidly and reliably by electrochemical methods. Ertl et al. (2000, 2003) used potassium ferricyanide as a redox probe. Escherichia coli was mixed with a solution of potassium ferricyanide after $15 \mathrm{~min}$ of interaction with antibiotics, and the electrical signal was measured by the chronoelectric method. The results were in complete agreement with the conventional paper diffusion method. This method can provide a report in $<25 \mathrm{~min}$. However, the $\mathrm{IC}_{50}$ values measured by electrochemical method were 100 times higher than the results obtained by standard turbidity method, and the electrodes were found to adsorb antibiotics during the test. Chotinantakul et al. (2014) improved the test protocol based on Ertl et al. The antibiotics were removed by centrifugation of $E$. coli after interaction with bacteria and resuspended in a test solution containing potassium ferricyanide, which gave the results of the drug sensitivity test in 3-6 h.

However, the detection of bacterial resistance using conventional commercial electrodes has the disadvantage of insufficient sensitivity. Therefore, improving the performance of electrodes can be a good way to improve the accuracy of detection. In this work, we modified the conventional glassy carbon electrode (GCE) with surface graphene ink, which can greatly improve the sensing performance of the electrode (Baghayeri, 2017; Zhang M. et al., 2020; Mohanraj et al., 2020; $\mathrm{Xu}$ et al., 2020). The modified electrode can detect the electrochemical reduction behavior of $E$. coli more sensitively. Likewise, the differences in the altered electrochemical behavior were amplified due to the influence of different antibiotics after This technique could potentially be applied for the evaluation of resistance for $E$. coli.

\section{MATERIALS AND METHODS}

All electrochemical measurements were carried out using a CHI660E working station. A three-electrode system was applied for all measurements. Specifically, a glassy carbon electrode (GCE), a Pt foil and an $\mathrm{Ag} / \mathrm{AgCl}$ electrode were used as working electrode, counter electrode and reference electrode, respectively. Escherichia coli J53 was purchased from Beijing Bio Bo Wei Biotechnology Co., Ltd. Ofloxacin, penicillin and cefepime was purchased from Sinopharm Chemical Reagent Co., Ltd. Graphene dispersion was purchased from Jiangsu XFNANO Materials Tech Co., Ltd. All other reagents used in this work were analytical grade and used without further purification. Phosphate buffer solution (PBS, 0.1 M) was prepared by mixed stock solutions of $0.1 \mathrm{M}$ disodium hydrogen phosphate and sodium dihydrogen phosphate until reach to the desired $\mathrm{pH}$.

Escherichia coli J53 was grown over night in a Luria Bertani (LB) medium $(100 \mathrm{ml})$ at $37^{\circ} \mathrm{C}$ with shaking. The cells of E. coli were collected after centrifugation and washed by PBS. The colony forming units (CFU) were then counted. Then, the E. coli was diluted by graphene dispersion to reach a desired CFU by stirring.

Electrode surface modification was conducted by drop coating of desired concentration of graphene-E. coli dispersion on the GCE surface and kept in a humid chamber for $1 \mathrm{~h}$ before analysis. Then, the electrode was inserted into a PBS and conducted a voltammetric scan. The E. coli modified GCE was prepared using a similar method but with out the mixing of graphene dispersion. 


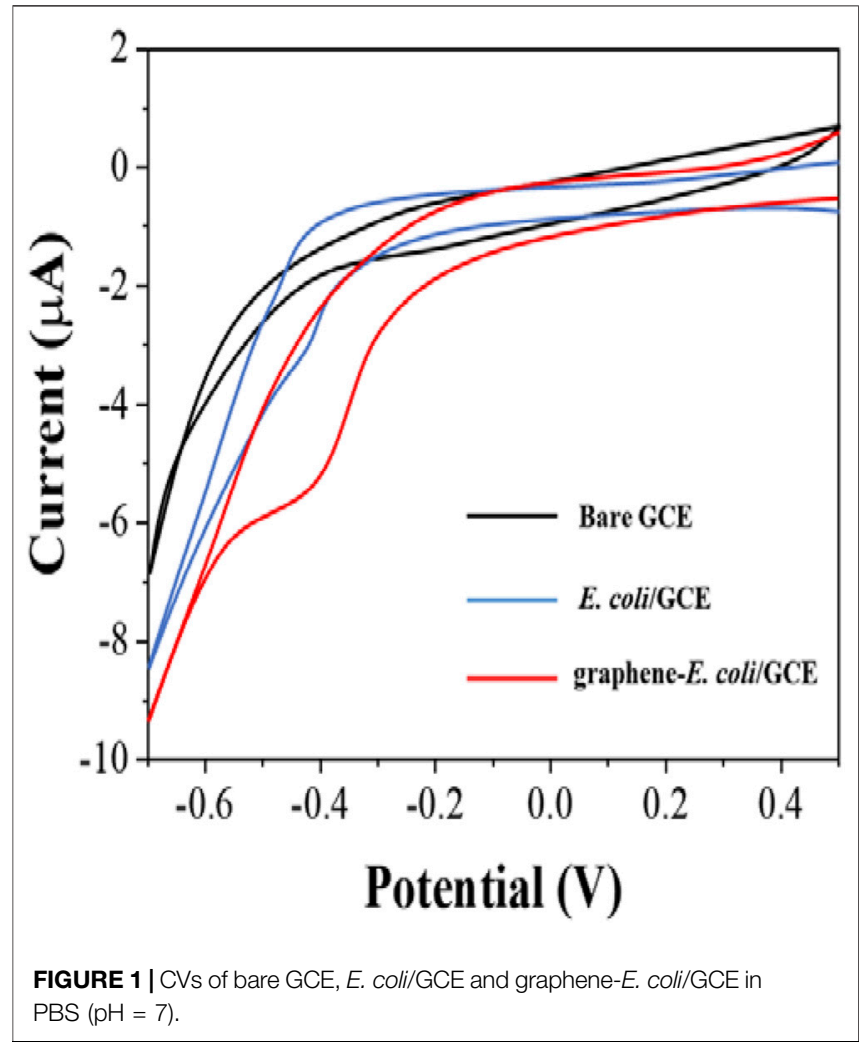

For antibiotic resistance tests, $5 \mu \mathrm{L}$ of ofloxacin, penicillin and cefepime solution was drop coated at graphene- $E$. coli modified GCE. Then, the electrode was kept in a humid chamber. The viability test was carried out at $1 \mathrm{~h}$ interval.

\section{RESULTS AND DISCUSSION}

Since bacterial cells have their own oxidoreductase system, which has been shown to be involved in electron transfer (Couto et al., 2018), we first investigated the direct electrochemical behavior of E. coli. First, we performed cyclic voltammetry $(\mathrm{CV})$ tests only $\times 10^{7} \mathrm{CFU} E$ coli with directly coated on the GCE surface (Figure 1). Comparing to bare GCE, we could see a clear reduction peak at around $-0.4 \mathrm{~V}$, which indicates that the electroactivity of bacterial cells undergoes surface electrode reaction. However, the reduction current of this reduction peak is not particularly pronounced and is only $3.2 \mu \mathrm{A}$. In contrast, the intensity of the reduction current of $E$. coli is significantly higher after co-mixing with graphene. There are two reasons for this increase. The first one is that the excellent electrical properties of graphene itself improve the electron transfer rate (Pourmadadi et al., 2019). The second is that the lamellar structure of graphene greatly enhances the electrochemically active area (Gupta et al., 2019). It enables more cells to participate in the electrochemical reaction after wrapping $E$. coli. Therefore, with the assistance of graphene, it became possible to evaluate the
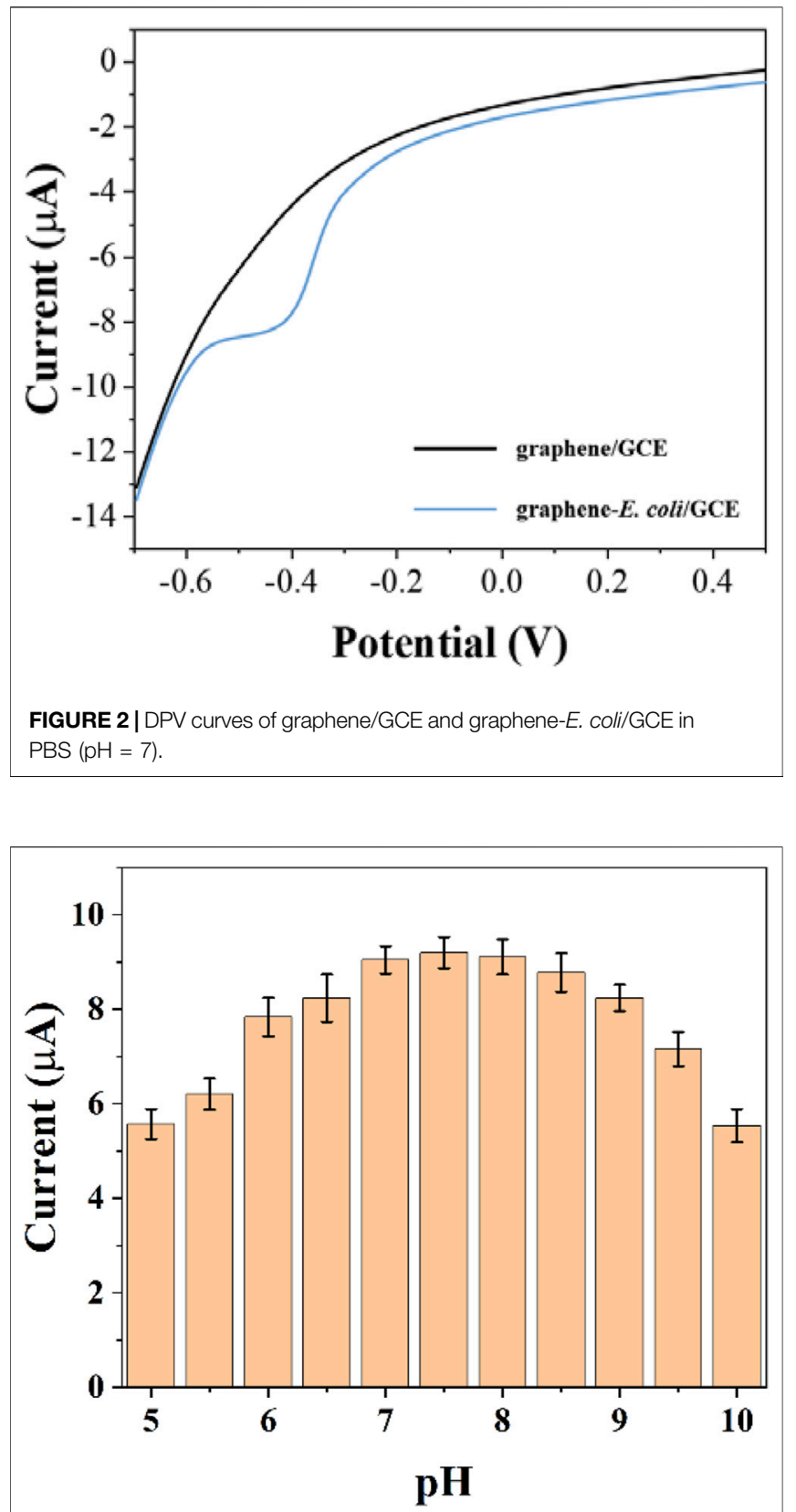

FIGURE 3|Reduction peak current of graphene-E. coli/GCE at different $\mathrm{pH}$ conditions $(n=3)$.

antibiotic resistance of $E$. coli cells from its electrochemical behavior.

After determining the electrochemical behavior of E. coli, we used the electrochemical reduction peak as a probe for cell viability evaluation. To make the detection more sensitive, we further investigated the electrodes with differential pulse voltammetry (DPV). Figure 2 shows the DPV curves of graphene/GCE and graphene-E. coli/GCE. It can be seen that graphene/GCE shows only a flat curve, but the curve of graphene-E. coli/GCE has a clear reduction peak. At the same 


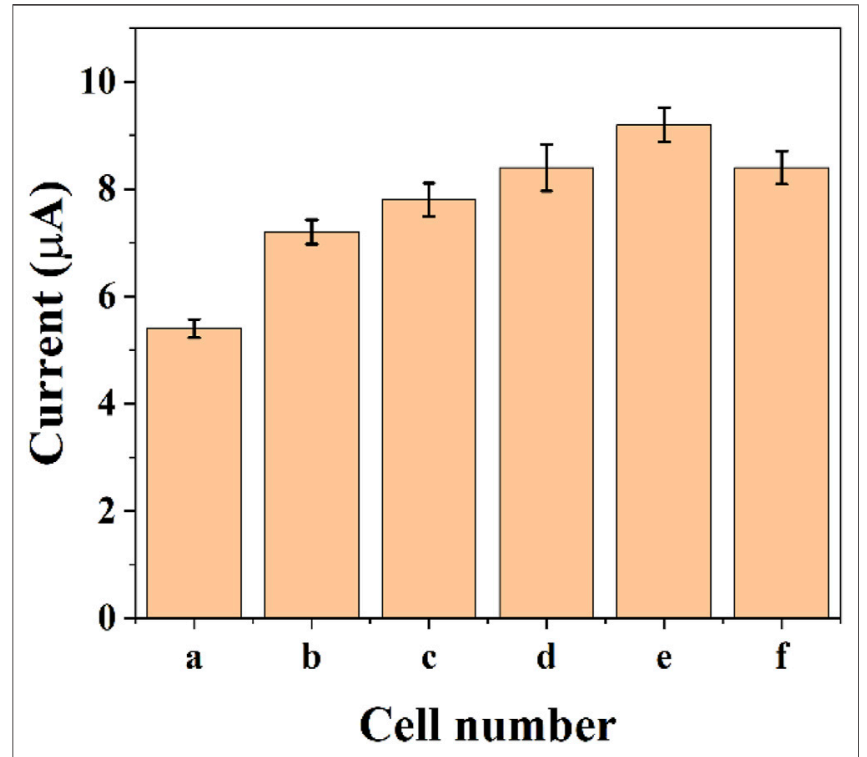

FIGURE 4 | Reduction peak current of graphene-E. coli/GCE at PBS with $1 \times 10^{5} \mathrm{CFU}$ (A), $5 \times 10^{5} \mathrm{CFU}$ (B), $1 \times 10^{6} \mathrm{CFU}$ (C), $5 \times 10^{6} \mathrm{CFU}$ (D), $1 \times$ $10^{7} \mathrm{CFU}(\mathbf{E})$, and $5 \times 10^{7} \mathrm{CFU}(\mathbf{F})(n=3)$.

time, the reduction peak on DPV has some shift against CV, which is due to the amplitude added by DPV (Vilas-Boas et al., 2019). We can see that the DPV test has a better signal-to-noise ratio than the $\mathrm{CV}$. This reduction reaction is catalyzed by some macromolecules in E. coli cells. The substances involved may be cell surface c-type cytochromes and bacterial outer membrane reductases, dehydrogenases and flavoproteins (Vinod et al., 2002).

The $\mathrm{pH}$ of the buffer solution can significant effect on electrochemistry. Electrochemically active substances have different electrochemical behaviors at different $\mathrm{pH}$ conditions. In the same time, the activity of $E$. coli is different in different $\mathrm{pH}$ environments. Therefore, it is necessary for us to optimize the $\mathrm{pH}$ conditions. Figure 3 shows the difference of reduction currents between $\mathrm{pH}$ 5-10. It can be seen that the intensity of the currents gradually increases as the acidic conditions move toward the neutral conditions. The current peaks reached the maximum at 7.5. As the $\mathrm{pH}$ environment gradually becomes alkaline, the current value of the reduction peak starts to decrease. We finally chose the optimal $\mathrm{pH}$ environment as 7.5.

The reduction current of DPV will also increase due to the increase in the number of cells. Figure 4 shows the assay with graphene- $E$. coli/GCE for $1 \times 10^{5} \mathrm{CFU}, 5 \times 10^{5} \mathrm{CFU}, 1 \times$ $10^{6} \mathrm{CFU}, 5 \times 10^{6} \mathrm{CFU}, 1 \times 10^{7} \mathrm{CFU}$, and $5 \times 10^{7} \mathrm{CFU}$. It can be seen that the reduction current increases as the number of cells increases. This may be due to the fact that more cells are involved in the electrochemical reaction. However, too many cells also lead to a decrease in the current, which is due to the fact that $E$. coli itself does not have a good conductivity. Too many cells form a thicker film, which hinders the transfer of electrons. These results are in accordance with works published recent years regards to the electrochemistry of
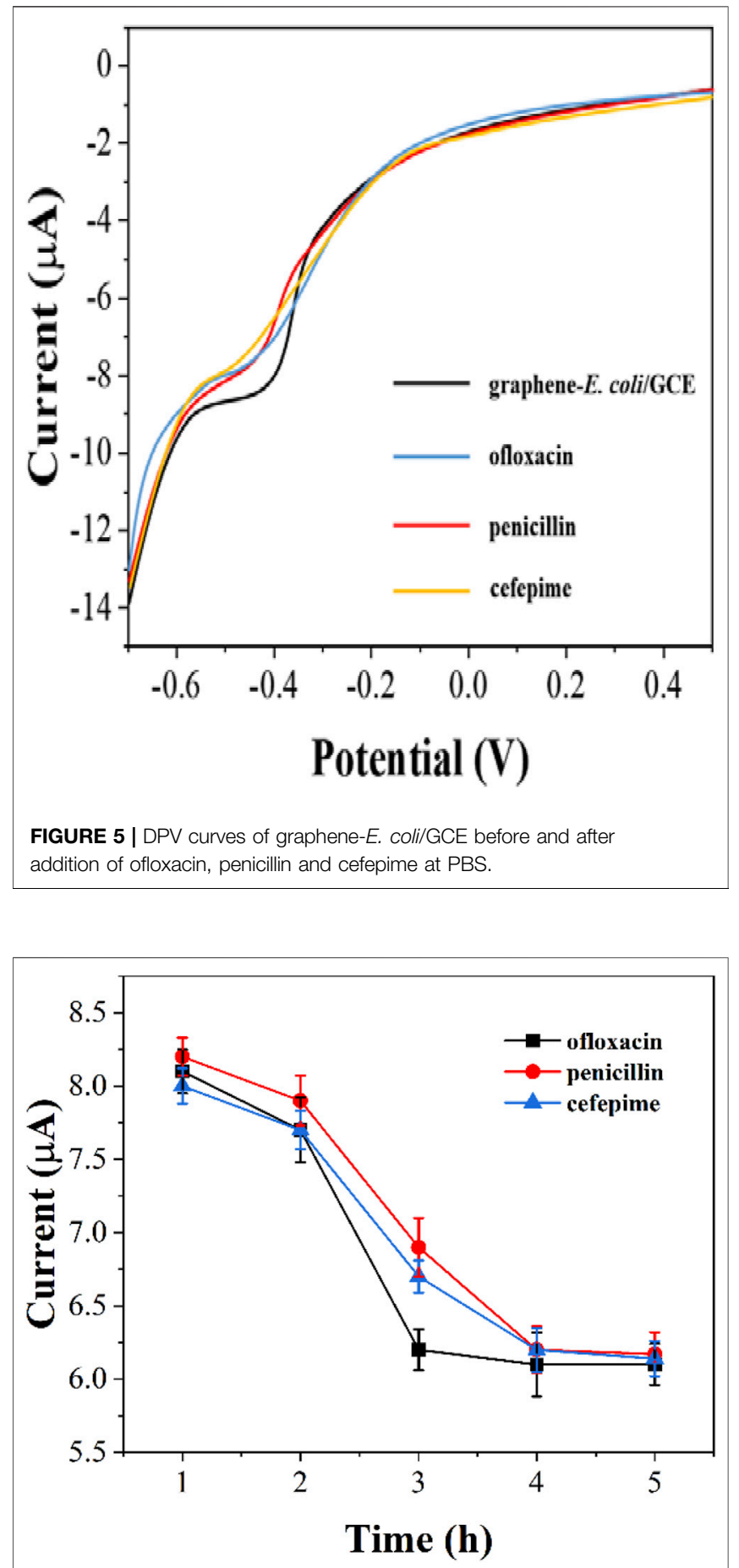

FIGURE 6 | Reduction peak currents of graphene-E. coli/GCE at PBS after addition of ofloxacin, penicillin and cefepime $(n=3)$.

E. coli cells (Setterington and Alocilja, 2011; Dos Santos et al., 2013). To reveal the maximum variability, we chose $1 \times 10^{7} \mathrm{CFU}$ as the optimal condition.

Since antibiotics can kill E. coli. The inactive E. coli is unable to perform effective electrochemical catalytic reaction. Therefore, 
the difference in reduction current can be used to detect the number of surviving E. coli on the electrode surface. However, E. coli possessing antibiotic resistance can survive in the presence of antibiotics and therefore the behavior of electrochemical reduction will receive only a small effect. In this work, we tested the susceptibility of $E$. coli to ofloxacin, penicillin and cefepime. Figure 5 shows the electrochemical behavior of graphene-E. coli/GCE $1 \mathrm{~h}$ after the addition of ofloxacin, penicillin and cefepime. It can be seen that there is a corresponding decrease in the reduction current in each curve compared to the electrochemical behavior without the addition of antibiotics. It represents a decrease in the number of cells able to participate in the electrochemically catalyzed reduction due to the destruction of E. coli by antibiotics and therefore a decrease in the current.

We monitored the bacterial inhibition of the three antibiotics. Figure 6 shows the electrochemical reduction currents at different times after the addition of antibiotics to graphene- $E$. coli/GCE. It can be seen that the electrochemical reduction current increases with time, indicating that the antibiotic continues to have an effect on $E$. coli. Ofloxacin after about $3 \mathrm{~h}$ The reduction current has no longer changes after $3 \mathrm{~h}$ after the addition of ofloxacin. The same was true for penicillin and cefepime, which took about $4 \mathrm{~h}$. We can observe a gradual loss of activity of $E$. coli during this process. However, if $E$. coli has antibiotic resistance, it can maintain the original intensity of the reduction current. Therefore, this technique could potentially be used to identify drug-resistant strains of E. coli.

\section{REFERENCES}

Abdullah, A., Asghar, A., Butt, M. S., Shahid, M., and Huang, Q. (2017). Evaluating the Antimicrobial Potential of green Cardamom Essential Oil Focusing on Quorum Sensing Inhibition of Chromobacterium Violaceum. J. Food Sci. Technol. 54, 2306-2315. doi:10.1007/s13197-017-2668-7

Alsaiari, N. S., Katubi, K. M. M., Alzahrani, F. M., Siddeeg, S. M., and Tahoon, M. A. (2021). The Application of Nanomaterials for the Electrochemical Detection of Antibiotics: A Review. Micromachines 12, 308. doi:10.3390/mi12030308

Baghayeri, M. (2017). Pt Nanoparticles/reduced Graphene Oxide Nanosheets as a Sensing Platform: Application to Determination of Droxidopa in Presence of Phenobarbital. Sensors Actuators B: Chem. 240, 255-263. doi:10.1016/j.snb. 2016.08.161

Bagheri, S. S., Peighambari, S. M., Soltani, M., and Malekan, M. (2019). RAPD-PCR and Drug Resistance Pattern of Staphylococcus aureus Isolates Recovered from Companion and Wild Birds. Iranj. Vet. Med. 13, 356-364. 10.22059/IJVM. 2019.282080.1004991

Bengtson, H. N., Homolka, S., Niemann, S., Reis, A. J., da Silva, P. E., Gerasimova, Y. V., et al. (2017). Multiplex Detection of Extensively Drug Resistant Tuberculosis Using Binary Deoxyribozyme Sensors. Biosens. Bioelectron. 94, 176-183. doi:10.1016/j.bios.2017.02.051

Chotinantakul, K., Suginta, W., and Schulte, A. (2014). Advanced Amperometric Respiration Assay for Antimicrobial Susceptibility Testing. Anal. Chem. 86, 10315-10322. doi:10.1021/ac502554s

Couto, R. A. S., Chen, L., Kuss, S., and Compton, R. G. (2018). Detection of Escherichia coli Bacteria by Impact Electrochemistry. Analyst 143, 4840-4843. doi:10.1039/c8an01675e

Dos Santos, M. B., Agusil, J., Prieto-Simón, B., Sporer, C., Teixeira, V., and Samitier, J. (2013). Highly Sensitive Detection of Pathogen Escherichia coli O157: H7 by Electrochemical Impedance Spectroscopy. Biosens. Bioelectron. 45, 174-180. doi:10.1016/j.bios.2013.01.009

\section{CONCLUSION}

In this work, we coated E. coli cells with a graphene dispersion, which was then immobilized on the electrode surface. This approach allows the evaluation of the activity of $E$. coli on the electrode surface. The electrocatalytic reduction current is the indicator in this evaluation. The current is proportional to the activity of the cells on the surface of the electrode according to the electrode. The antibiotic has an effect on the cells that result in the decreasing of the electrocatalytic reduction signal. Therefore, this strategy can be used to evaluate the resistance of cells to antibiotics. After optimization of the parameters, we successfully evaluated the resistance of $E$. coli to ofloxacin, penicillin and cefepime.

\section{DATA AVAILABILITY STATEMENT}

The original contributions presented in the study are included in the article/Supplementary Material, further inquiries can be directed to the corresponding author.

\section{AUTHOR CONTRIBUTIONS}

CL and FS conducted the experiments and analysis. CL and FSwrote the manuscript. All authors read and approved the manuscript.

Ertl, P., Unterladstaetter, B., Bayer, K., and Mikkelsen, S. R. (2000). Ferricyanide Reduction byEscherichiacoli: Kinetics, Mechanism, and Application to the Optimization of Recombinant Fermentations. Anal. Chem. 72, 4949-4956. doi:10.1021/ac000358d

Ertl, P., Wagner, M., Corton, E., and Mikkelsen, S. R. (2003). Rapid Identification of Viable Escherichia coli Subspecies with an Electrochemical Screen-Printed Biosensor Array. Biosens. Bioelectron. 18, 907-916. doi:10.1016/s09565663(02)00206-3

Farooq, U., Ullah, M. W., Yang, Q., Aziz, A., Xu, J., Zhou, L., et al. (2020). Highdensity Phage Particles Immobilization in Surface-Modified Bacterial Cellulose for Ultra-sensitive and Selective Electrochemical Detection of Staphylococcus aureus. Biosens. Bioelectron. 157, 112163. doi:10.1016/j.bios.2020.112163

Fu, Y., Zhou, X., Duan, X., Liu, C., Huang, J., Zhang, T., et al. (2020). A LAMPBased Ratiometric Electrochemical Sensing for Ultrasensitive Detection of Group B Streptococci with Improved Stability and Accuracy. Sensors Actuators B: Chem. 321, 128502. doi:10.1016/j.snb.2020.128502

Gorlenko, C. L., Kiselev, H. Y., Budanova, E. V., Zamyatnin, A. A., and Ikryannikova, L. N. (2020). Plant Secondary Metabolites in the Battle of Drugs and Drug-Resistant Bacteria: New Heroes or Worse Clones of Antibiotics? Antibiotics 9, 170. doi:10.3390/antibiotics 9040170

Gupta, A., Bhardwaj, S. K., Sharma, A. L., and Deep, A. (2019). A Graphene Electrode Functionalized with Aminoterephthalic Acid for Impedimetric Immunosensing of Escherichia coli. Microchim. Acta 186, 1-7. doi:10.1007/ s00604-019-3952-1

Hu, C., Kalsi, S., Zeimpekis, I., Sun, K., Ashburn, P., Turner, C., et al. (2017). Ultrafast Electronic Detection of Antimicrobial Resistance Genes Using Isothermal Amplification and Thin Film Transistor Sensors. Biosens. Bioelectron. 96, 281-287. doi:10.1016/j.bios.2017.05.016

Hu, K., Huang, X., Jiang, Y., Fang, W., and Yang, X. (2010). Monoclonal Antibody Based Enzyme-Linked Immunosorbent Assay for the Specific Detection of Ciprofloxacin and Enrofloxacin Residues in Fishery Products. Aquaculture 310, 8-12. doi:10.1016/j.aquaculture.2010.08.008 
Karimi-Maleh, H., Alizadeh, M., Orooji, Y., Karimi, F., Baghayeri, M., Rouhi, J., et al. (2021a). Guanine-Based DNA Biosensor Amplified with Pt/ SWCNTs Nanocomposite as Analytical Tool for Nanomolar Determination of Daunorubicin as an Anticancer Drug: A Docking/ Experimental Investigation. Ind. Eng. Chem. Res. 60, 816-823. doi:10. 1021/acs.iecr.0c04698

Karimi-Maleh, H., Karimi, F., Malekmohammadi, S., Zakariae, N., Esmaeili, R., Rostamnia, S., et al. (2020). An Amplified Voltammetric Sensor Based on Platinum Nanoparticle/polyoxometalate/two-Dimensional Hexagonal boron Nitride Nanosheets Composite and Ionic Liquid for Determination of N-Hydroxysuccinimide in Water Samples. J. Mol. Liquids 310, 113185. doi:10.1016/j.molliq.2020.113185

Karimi-Maleh, H., Orooji, Y., Karimi, F., Alizadeh, M., Baghayeri, M., Rouhi, J., et al. (2021b). A Critical Review on the Use of Potentiometric Based Biosensors for Biomarkers Detection. Biosens. Bioelectron. 184, 113252. doi:10.1016/j.bios. 2021.113252

Karimi-Maleh, H., Yola, M. L., Atar, N., Orooji, Y., Karimi, F., Senthil Kumar, P., et al. (2021c). A Novel Detection Method for Organophosphorus Insecticide Fenamiphos: Molecularly Imprinted Electrochemical Sensor Based on CoreShell Co3O4@MOF-74 Nanocomposite. J. Colloid Interf. Sci. 592, 174-185. doi:10.1016/j.jcis.2021.02.066

Khan, M. Z. H., Hasan, M. R., Hossain, S. I., Ahommed, M. S., and Daizy, M. (2020). Ultrasensitive Detection of Pathogenic Viruses with Electrochemical Biosensor: State of the Art, 166. Biosens. Bioelectron. 112431. doi:10.1016/j.bios. 2020.112431

Mishra, M., Arukha, A. P., Patel, A. K., Behera, N., Mohanta, T. K., and Yadav, D. (2018). Multi-drug Resistant Coliform: Water Sanitary Standards and Health Hazards. Front. Pharmacol. 9, 311. doi:10.3389/ fphar.2018.00311

Mohanraj, J., Durgalakshmi, D., Rakkesh, R. A., Balakumar, S., Rajendran, S., and Karimi-Maleh, H. (2020). Facile Synthesis of Paper Based Graphene Electrodes for point of Care Devices: a Double Stranded DNA (dsDNA) Biosensor. J. Colloid Interf. Sci. 566, 463-472. doi:10.1016/j.jcis.2020. 01.089

Mulat, M., Pandita, A., and Khan, F. (2019). Medicinal Plant Compounds for Combating the Multi-Drug Resistant Pathogenic Bacteria: a Review. Cpb 20, 183-196. doi:10.2174/1872210513666190308133429

Osman, K. M., da Silva Pires, Á., Franco, O. L., Saad, A., Hamed, M., Naim, H., et al. (2021). Nile tilapia (Oreochromis niloticus) as an Aquatic Vector for Pseudomonas Species of Medical Importance: Antibiotic Resistance Association with Biofilm Formation, Quorum Sensing and Virulence. Aquaculture 532, 736068. doi:10.1016/j.aquaculture.2020.736068

Phung, T. T. B., Chu, S. V., Vu, S. T., Pham, H. T., Nguyen, H. M., Nguyen, H. D., et al. (2020). COLD-PCR Method for Early Detection of Antiviral DrugResistance Mutations in Treatment-Naive Children with Chronic Hepatitis B. Diagnostics 10, 491. doi:10.3390/diagnostics10070491

Pourmadadi, M., Shayeh, J. S., Omidi, M., Yazdian, F., Alebouyeh, M., and Tayebi, L. (2019). A Glassy Carbon Electrode Modified with Reduced Graphene Oxide and Gold Nanoparticles for Electrochemical Aptasensing of Lipopolysaccharides from Escherichia coli Bacteria. Microchim. Acta 186, 1-8. doi:10.1007/s00604-019-3957-9

Sedki, M., Hassan, R. Y. A., Hefnawy, A., and El-Sherbiny, I. M. (2017). Sensing of Bacterial Cell Viability Using Nanostructured Bioelectrochemical System: rGOHyperbranched Chitosan Nanocomposite as a Novel Microbial Sensor Platform. Sensors Actuators B: Chem. 252, 191-200. doi:10.1016/j.snb.2017. 05.163

Setterington, E. B., and Alocilja, E. C. (2011). Rapid Electrochemical Detection of Polyaniline-Labeled Escherichia coli O157:H7. Biosens. Bioelectron. 26, 2208-2214. doi:10.1016/j.bios.2010.09.036

Sharaha, U., Rodriguez-Diaz, E., Riesenberg, K., Bigio, I. J., Huleihel, M., and Salman, A. (2017). Using Infrared Spectroscopy and Multivariate Analysis to Detect Antibiotics' ResistantEscherichia coliBacteria. Anal. Chem. 89, 8782-8790. doi:10.1021/acs.analchem.7b01025

Simioni, N. B., Silva, T. A., Oliveira, G. G., and Fatibello-Filho, O. (2017). A Nanodiamond-Based Electrochemical Sensor for the Determination of Pyrazinamide Antibiotic. Sensors Actuators B: Chem. 250, 315-323. doi:10. 1016/.j.snb.2017.04.175
Sun, Y., Zhao, C., Niu, J., Ren, J., and Qu, X. (2020). Colorimetric Band-Aids for point-of-care Sensing and Treating Bacterial Infection. ACS Cent. Sci. 6, 207-212. doi:10.1021/acscentsci.9b01104

Vilas-Boas, Â., Valderrama, P., Fontes, N., Geraldo, D., and Bento, F. (2019). Evaluation of Total Polyphenol Content of Wines by Means of Voltammetric Techniques: Cyclic Voltammetry vs Differential Pulse Voltammetry. Food Chem. 276, 719-725. doi:10.1016/j.foodchem.2018.10.078

Vinod, M. P., Bellur, P., and Becker, D. F. (2002). Electrochemical and Functional Characterization of the Proline Dehydrogenase Domain of the PutA Flavoprotein fromEscherichia Coli†. Biochemistry 41, 6525-6532. doi:10. 1021/bi025706f

Wang, M., Hu, M., Liu, J., Guo, C., Peng, D., Jia, Q., et al. (2019). Covalent Organic Framework-Based Electrochemical Aptasensors for the Ultrasensitive Detection of Antibiotics. Biosens. Bioelectron. 132, 8-16. doi:10.1016/j.bios. 2019.02.040

Wang, Y., Dong, W., Odah, K. A., Kong, L., and Ma, H. (2019). Transcriptome Analysis Reveals AI-2 Relevant Genes of Multi-Drug Resistant Klebsiella pneumoniae in Response to Eugenol at Sub-MIC. Front. Microbiol. 10, 1159. doi:10.3389/fmicb.2019.01159

Waseem, H., Jameel, S., Ali, J., Saleem Ur Rehman, H., Tauseef, I., Farooq, U., et al. (2019). Contributions and Challenges of High Throughput qPCR for Determining Antimicrobial Resistance in the Environment: a Critical Review. Molecules 24, 163. doi:10.3390/molecules 24010163

Wu, W., Wu, M., Zhou, J., Xu, Y., Li, Z., Yao, Y., et al. (2020). Development of Electrochemical Sensor for Fast Liquor Authentication. Sens. Mater. 32, 2941-2948. doi:10.18494/sam.2020.2972

Xu, Y., Lu, Y., Zhang, P., Wang, Y., Zheng, Y., Fu, L., et al. (2020). Infrageneric Phylogenetics Investigation of Chimonanthus Based on Electroactive Compound Profiles. Bioelectrochemistry 133, 107455. doi:10.1016/j. bioelechem.2020.107455

Zhang, L., Liang, W., Ran, Q., Liu, F., Chen, D., Xiong, Y., et al. (2020). Ultrasensitive Detection of NDM-1 Resistant Bacteria Based on Signal Amplification with sandwich-type LNA Electrochemical Biochips. Sensors Actuators B: Chem. 306, 127556. doi:10.1016/j.snb.2019.127556

Zhang, M., Pan, B., Wang, Y., Du, X., Fu, L., Zheng, Y., et al. (2020). Recording the Electrochemical Profile of Pueraria Leaves for Polyphyly Analysis. ChemistrySelect 5, 5035-5040. doi:10.1002/slct.202001100

Zhang, X., Yang, R., Li, Z., Zhang, M., Wang, Q., Xu, Y., et al. (2020). Electroanalytical Study of Infrageneric Relationship of Lagerstroemia Using Glassy Carbon Electrode Recorded Voltammograms. Rmiq 19, 281-291. doi:10. 24275/rmiq/bio1750

Zhao, L., Liu, Y., Zhang, Z., Wei, J., Xie, S., and Li, X. (2020). Fibrous Testing Papers for Fluorescence Trace Sensing and Photodynamic Destruction of AntibioticResistant Bacteria. J. Mater. Chem. B 8, 2709-2718. doi:10.1039/d0tb00002g

Zhi-bin, L., Min, W., Xiao-cui, W., Min, H., He-ping, X., and Qing, Z. (2021). The Value of PCR-Reverse Dot Blot Hybridization in Detecting the Drug Resistance of Mycobacterium tuberculosis in Sputum Specimens of Retreatment SmearPositive Pulmonary Tuberculosis Patients. Chin. J. Antituberc. 43, 47. doi:10. 17343/sdutfd.534941

Zhou, T., Han, H., Liu, P., Xiong, J., Tian, F., and Li, X. (2017). Microbial Fuels CellBased Biosensor for Toxicity Detection: A Review. Sensors 17, 2230. doi:10. 3390/s17102230

Zhuang, J., Wang, S., Tan, Y., Xiao, R., Chen, J., Wang, X., et al. (2019). Degradation of Sulfadimethoxine by Permanganate in Aquatic Environment: Influence Factors, Intermediate Products and Theoretical Study. Sci. Total Environ. 671, 705-713. doi:10.1016/j.scitotenv.2019.03.277

Conflict of Interest: The authors declare that the research was conducted in the absence of any commercial or financial relationships that could be construed as a potential conflict of interest.

Copyright (c) $2021 \mathrm{Li}$ and Sun. This is an open-access article distributed under the terms of the Creative Commons Attribution License (CC BY). The use, distribution or reproduction in other forums is permitted, provided the original author(s) and the copyright owner(s) are credited and that the original publication in this journal is cited, in accordance with accepted academic practice. No use, distribution or reproduction is permitted which does not comply with these terms. 